\title{
A FORMAÇÃO DOCENTE E SUA RELAÇÃO COM A INSERÇÃO PROFISSIONAL: POLÍTICAS DOCENTES NA REDE MUNICIPAL DO RIO DE JANEIRO
}

\begin{abstract}
AVELAR, Michele Silva de Avelar (Brasil, Rio de Janeiro, Rio de Janeiro) ${ }^{1 *}$; SILVA, Yrlla Ribeiro de Oliveira Carneiro da (Brasil, Rio de Janeiro, Rio de Janeiro) ${ }^{1 * *}$; NASCIMENTO, Maria das Graças Chagas de Arruda (Brasil, Rio de Janeiro, Rio de Janeiro) ${ }^{1+* *}$ 1 Universidade Federal do Rio de Janeiro ORCID ID: https://orcid.org/0000-0002-0298-7932* ORCID ID: https://orcid.org/0000-0003-4762-9343** ORCID ID: https://orcid.org/0000-0002-6334-4121**

RESUMO

Este artigo apresenta alguns resultados de uma pesquisa que teve por objetivo analisar as ações propostas pelo sistema municipal de ensino do Rio de Janeiro, a partir de 2012, voltadas para a inserção profissional de professores e sua contribuição para o trabalho docente no início da carreira. Foca-se o curso de "Formação Básica" oferecido durante o processo de seleção de novos docentes. Como recursos metodológicos, foram utilizados questionário e entrevistas, tendo sido ouvidos 51 professores, cinco diretoras de escolas e quatro gestoras do nível central. Os principais resultados apontaram para um momento híbrido e um movimento de mudanças no processo de implementação de uma formação docente que se quer afirmar como política de estado.
\end{abstract}

PALAVRAS-CHAVE

Trabalho docente. Professor iniciante. Indução profissional. Formação Básica.

\section{TEACHER TRAINING AND ITS RELATION WITH THEIR PROFESSIONAL INSERTION: TEACHING POLICIES IN THE MUNICIPAL EDUCATIONAL SYSTEM OF RIO DE JANEIRO}

\begin{abstract}
This article presents some results of a research that aimed at analyzing the actions proposed by the municipal educational system of Rio de Janeiro, from 2012 onwards, related to the professional insertion of teachers and their contribution to the teaching work at the beginning of the career. In this article our focus is the "Basic Training" course offered during the selection process for new teachers. A questionnaire and interviews were used as methodological resources. Fifty-one teachers, five school principals, and four central level managers were heard. The main results pointed to a hybrid moment and to a movement for changes in the implementation of teacher training procedures aimed at becoming a State policy.
\end{abstract}

\section{KEYWORDS}

Teaching assignment. Initial teachers. Professional incitement. Professional Inducement. Basic formation. 


\title{
LA FORMACIÓN DOCENTE Y SU RELACIÓN CON LA INSERCIÓN PROFESIONAL: POLÍTICAS DOCENTES EN LA RED MUNICIPAL DE RIO DE JANEIRO
}

\begin{abstract}
RESUMEN
Este artículo presenta algunos resultados de una encuesta que tuvo por objetivo analizar las acciones propuestas por el sistema municipal de enseñanza de Rio de Janeiro, a partir de 2012, orientadas a la inserción profesional de profesores y su contribución al trabajo docente al inicio de la carrera. Se enfoca el curso de "Formación Básica" ofrecido durante el proceso de selección de nuevos docentes. Como recursos metodológicos, se utilizaron cuestionario y entrevistas, habiendo sido escuchados 51 profesores, cinco directoras de escuelas y cuatro gestoras del nivel central. Los principales resultados apuntaron a un momento híbrido y un movimiento de cambios en el proceso de implementación de una formación docente que se quiere afirmar como política de estado.
\end{abstract}

\section{PALABRAS CLAVE}

Trabajo docente. Profesor iniciante. Instrucción profesional. Formación básica.

\section{INTRODUÇÃO}

As novas exigências que se apresentam ao trabalho dos professores e das escolas na atualidade, a complexidade crescente, a precarização das condições de trabalho e a desvalorização social do magistério colocam em evidência a importante questão das políticas docentes, voltadas para o apoio e a valorização dos professores, implementadas nos últimos tempos em nosso país.

Tal cenário apresenta novos desafios para os professores e para as políticas docentes: além da implementação de uma real valorização do magistério e da busca de soluções para os problemas estruturais que afetam a educação em nosso país, torna-se necessária uma maior atenção com a formação e o desenvolvimento profissional dos professores. A nosso ver, tal atenção torna-se crucial, especialmente, no momento de inserção profissional, quando os docentes precisam fazer "[...] a transição de estudantes para professores" (GARCIA, 2010, p. 28), o que certamente provoca muitas tensões e dúvidas.

Alguns autores, tais como Dubar (1997), Huberman (2000), Tardif e Raymond (2000), têm desenvolvido estudos sobre a socialização profissional, referindo-se ao início desse processo como um momento de choque com a realidade, "sobrevivência", descoberta e grande aprendizado. Para Dubar (1997, p. 136), "[...] esse momento se 
caracteriza por ser uma espécie de imersão na cultura profissional que aparece brutalmente como o inverso da cultura profana e coloca a angustiante questão da forma com que as duas culturas interagem no interior do indivíduo". Tal confronto, denominado na literatura como "choque do real" ou "choque cultural", constitui um dos fatores que caracterizam o momento de entrada na profissão, gerando estratégias individuais ou coletivas para a sua superação, que compõem o aspecto de sobrevivência ao qual se refere Huberman (2000).

Segundo Huberman (2000, p. 39), o aspecto da descoberta "[...] traduz o entusiasmo inicial, a experimentação, a exaltação por estar, finalmente, em situação de responsabilidade (ter a sua sala de aula, os seus alunos, o seu programa), por se sentir colega num determinado corpo profissional". A experiência nova proporciona aos professores, progressivamente, maiores certezas em relação ao trabalho, possibilitando assim a sua integração no ambiente profissional (a escola e a sala de aula) e confirmando sua capacidade de ensinar (TARDIF; RAYMOND, 2000).

Há a necessidade de os sistemas públicos de ensino promoverem ações formativas de indução profissional que possam favorecer uma efetiva articulação entre a formação inicial e o início do exercício do trabalho, direcionadas aos que estreiam na profissão, favorecendo, dessa forma, um processo coletivo de desenvolvimento profissional.

Constata-se, a partir dessas considerações, que, ainda que tenha ocorrido grande avanço no que se refere à oferta de ações formativas pelos sistemas de ensino, muito ainda resta a ser feito no que diz respeito à qualidade e efetividade dessas ações para mudanças nas práticas dos professores.

Assim, parece-nos relevante e urgente o estudo das ações e políticas públicas dirigidas aos professores em nosso país, especialmente aquelas que se referem à formação continuada, à inserção profissional, à aproximação entre a formação e as realidades do trabalho docente. Nesse cenário, este artigo apresenta resultados da pesquisa realizada que buscou investigar a experiência do município do Rio de Janeiro na implementação do programa de Formação Básica, oferecido como uma das etapas do concurso público que seleciona os futuros professores da rede municipal.

Educação \& Formação, Fortaleza, v. 4, n. 11, p. 179-196 maio/ago. 2019 


\title{
2 O CONTEXTO E O PERCURSO METODOLÓGICO DA PESQUISA
}

Em pesquisa anteriormente desenvolvida, foi-nos anunciada, por uma professora que atuava no nível central do sistema municipal de ensino do Rio de Janeiro, a implementação de uma política voltada para professores em início de carreira nessa rede. Dentre as iniciativas mencionadas estava a criação de uma escola de formação de professores, no ano de 2012, a Escola de Formação do Professor Carioca - Paulo Freire, que ficaria responsável pela coordenação das ações de acompanhamento, formação e desenvolvimento profissional a partir de então.

A Escola foi criada em 2012 pelo Decreto n. 35.602, de 9 de maio de 2012. Consoante publicação em seu sítio eletrônico ${ }^{1}$, trata-se de um espaço de produção de saberes e práticas pedagógicas para subsidiar o planejamento e a implementação da Política de Formação do Professor Carioca.

A Escola Paulo Freire está instalada na Escola Municipal Rivadávia Corrêa, no centro da cidade do Rio de Janeiro. No que se refere à estrutura organizacional, é formada pela:

\begin{abstract}
Gerência de Formação Básica, que promove ações formativas para professores ingressantes na Rede Pública Municipal de Ensino, como uma etapa do processo seletivo para o ingresso na rede; pela Gerência de Formação Continuada, que promove ações para os professores em exercício, nas modalidades presencial, semipresencial e à distância e pelo Centro de Referência da Educação Pública da Cidade do Rio de Janeiro - Anísio Teixeira (CREPAT), que dispõe de importante acervo sobre a história da Educação Pública na Cidade do Rio de Janeiro. (RIO DE JANEIRO, 2016, s.p.).
\end{abstract}

A Escola Paulo Freire teve como primeira gestora a professora Sônia Mercadante e sua inauguração se deu no âmbito do governo de Eduardo Paes². Referindo-se à inauguração da Escola, a então secretária de educação, Claudia Costin, assinalou: "O centro de formação tem por objetivo valorizar e capacitar os professores do município do Rio de Janeiro, possibilitando uma formação sólida e continuada nas diversas áreas do conhecimento, atendendo assim as necessidades dos alunos da Rede" (RIO EDUCA, 2012, s.p.).

1 Disponível em: <http://epf.rioeduca.net/sobrenos.html>. Acesso em: 22 abr. 2019.

2 Eduardo Paes elegeu-se como prefeito da cidade do Rio de Janeiro pelo Partido do Movimento Democrático Brasileiro pela primeira vez em 2009-2012, sendo reeleito pelo mesmo partido para o mandato 2013-2016.

Educação \& Formação, Fortaleza, v. 4, n. 11, p. 179-196 maio/ago. 2019

DOI: https://doi.org/10.25053/redufor.v4i11.1031

http://seer.uece.br/redufor 
Quanto à estrutura organizacional interna, a Escola Paulo Freire possui uma equipe gestora composta por uma gerência geral e três "gerências" específicas 3 : a de Formação Básica, a de Formação Continuada e a do CREP-AT (Centro de Referência da Educação Pública da Cidade do Rio de Janeiro - Anísio Teixeira), conforme o anexo 1 do Decreto n. 35.602, referente à criação desses cargos e suas competências.

De acordo com o anexo 1, é de competência da Gerência de Formação Básica:

\begin{abstract}
Definir conteúdo e critérios de aprovação no curso de Formação Básica para ingresso no quadro do magistério; gerenciar, executar e monitorar o curso de formação básica, pré-requisito para o ingresso no quadro do magistério; certificar os professores considerados aptos a ingressar na Rede Pública Municipal de Ensino. (RIO DE JANEIRO, 2012, p. 4).
\end{abstract}

Assim, fica determinado que a essa gerência cabe, fundamentalmente, planejar e executar um curso a ser oferecido aos professores candidatos ao sistema municipal de ensino - etapa que integra, a partir de então, o processo seletivo para esse sistema.

A Gerência de Educação Continuada é responsável por todas as ações formativas oferecidas pela Secretaria Municipal de Educação (SME) aos professores após o ingresso no sistema. Já o CREP-AT é responsável por gerir e disponibilizar ao público interno e externo o acervo histórico da educação pública carioca.

Para fins deste artigo, apenas os dados coletados junto à Gerência de Formação Básica serão considerados, por se tratar da gerência responsável pelo programa de Formação Básica, foco de nosso estudo.

A coleta das informações foi feita inicialmente através da consulta aos documentos oficiais que instituem e regulamentam as ações da SME voltadas para a inserção e o desenvolvimento profissional. Em seguida, foram realizadas entrevistas com as professoras gestoras que atuavam na Escola Paulo Freire, com a finalidade de mapear as ações voltadas para a inserção profissional desenvolvidas desde 2012, bem como de compreender as concepções que orientaram as referidas ações. Tiveram também como objetivo levantar informações prévias que subsidiaram a elaboração do questionário posteriormente aplicado aos professores.

3 Atualmente, a Escola Paulo Freire é composta por uma Direção-Geral e seis gerências: Gerência de Formação Inicial, Gerência de Formação Continuada do Professor Regente, Gerência de Formação Continuada da Equipe Gestora, Gerência de Desenvolvimento e Treinamento Técnico-Administrativo, Gerência de Fomento à Pesquisa e Centro de Referência da Educação Pública - Anísio Teixeira.

Educação \& Formação, Fortaleza, v. 4, n. 11, p. 179-196 maio/ago. 2019

DOI: https://doi.org/10.25053/redufor.v4i11.1031

http://seer.uece.br/redufor 
Paralelamente, consultamos os diários oficiais da prefeitura do Rio de Janeiro para o levantamento dos professores convocados à posse do cargo de professores do primeiro segmento do ensino fundamental a partir de 2012. Assim, levantamos 325 nomes de professores convocados pela SME entre 2012 e outubro de 2015. Tais professores haviam passado pelo curso de "Formação Básica" como uma das etapas do processo seletivo para o ingresso na rede.

Passamos então ao trabalho de localização desses profissionais conforme suas lotações, com base numa listagem de e-mails institucionais. O caminho para chegarmos aos sujeitos da pesquisa foi complexo, visto que não dispúnhamos de informações mais específicas sobre eles que fossem fornecidas pela própria SME. Assim, uma quantidade bastante expressiva dos professores que constava da primeira listagem não foi localizada através de nossos contatos. Localizamos 92 professores que atendiam aos critérios da pesquisa, aos quais enviamos um questionário on-line (Survey Monkey). Esse questionário foi respondido por 51 desses profissionais, o que representou uma taxa de retorno de $60,7 \%$ nessa plataforma.

Após a devolutiva dos questionários, demos início a uma nova etapa do trabalho de campo, realizando alguns grupos de discussão, para os quais foram convidados aqueles professores que já haviam respondido ao questionário. Foram ainda realizadas entrevistas com cinco diretoras de escolas onde trabalhavam professores participantes da pesquisa. Elas atuavam em escolas que pertenciam às Coordenadorias Regionais de Educação (CREs) onde encontramos uma maior participação de sujeitos na pesquisa. Escolhidemos uma escola da primeira CRE, região central da cidade; uma da segunda, localizada na região sul; duas escolas da nona e uma da décima CRE, ambas na região oeste da cidade e detentoras da maioria dos professores e escolas participantes (21 das 29 escolas encontravam-se nessa região da cidade).

Dessa forma, os sujeitos da pesquisa estavam distribuídos em três grupos. $O$ primeiro grupo composto pelas professoras gestoras da Escola Paulo Freire, entrevistado com o intuito de compreender as propostas de formação, sua concepção e execução. $O$ segundo grupo, foco principal deste estudo, formado pelos professores ingressantes na rede municipal de ensino, trouxe informações a respeito dos impactos do curso de Formação Básica na constituição de sua identidade profissional e em sua prática pedagógica. Já o último grupo, representado pelas diretoras de escolas em que havia 
professores ingressantes, contribuiu com a perspectiva da gestão que recebia os novos docentes.

\section{A "FORMAÇÃO BÁSICA" NA ESCOLA PAULO FREIRE}

Umas das ações que integram a política implementada é um curso oferecido aos candidatos a ocuparem uma vaga na rede municipal de ensino no decorrer do processo seletivo para tal.

Quanto à oferta do curso de Formação Básica aos professores ingressantes na rede municipal através da Escola Paulo Freire, percebemos que há preocupação quanto à formação específica dos profissionais antes de iniciarem o exercício da docência. $O$ ambiente é voltado ao processo de aproximação dos conhecimentos teóricos adquiridos na formação inicial e à prática a ser desenvolvida na escola, visando minimizar o tão amplamente abordado "choque de realidade" vivido pelos professores ingressantes na profissão (CAVACO, 1993; HUBERMAN, 2000; MARCELO, 1999; TARDIF, 2002).

Esse curso é oferecido aos professores que foram aprovados na primeira etapa do processo seletivo (prova escrita) para o ingresso na rede municipal. Em sua primeira versão (modalidade cursada pelos professores que participaram da pesquisa), o curso era de 80 horas, distribuídas em 10 dias (de segunda a sexta-feira, durante duas semanas). Para a sua realização, os professores receberam uma bolsa no valor de $50 \%$ do salário base de um professor da rede.

Huberman (2000) destaca que a iniciação na docência é um período que impõe ao professor muitos desafios, e este precisa criar "estratégias de sobrevivência". Essas estratégias podem ser coletivas e individuais e a formação desses profissionais pode ser considerada uma estratégia coletiva.

Chamamos de indução profissional docente o apoio e acompanhamento intencional e institucionalizado voltado aos professores em início de carreira no momento de suas inserção profissional. A inserção profissional é esse momento de transição, de ingresso na carreira. Ela poderá se dar com ou sem acompanhamento especial e institucional, ou seja, com ou sem indução profissional.

A experiência de formação básica da Escola Paulo Freire pode ser considerada relativamente nova no cenário carioca e até brasileiro, mas encontramos, na literatura 
especializada, muitas experiências internacionais de formação específica para os professores iniciantes e ainda algumas nacionais.

$\mathrm{Na}$ Finlândia, por exemplo, o programa de indução (termo utilizado em diversos países para caracterizar o período de formação e acompanhamento dos professores iniciantes) começou na década de 1990 e tem como base três conceitos-chave: formação, supervisão e colaboração (ROLDÃO; REIS; COSTA, 2012). Outros países criaram, entre as décadas de 80 e 90 do século passado, centros específicos de formação de professores. Os Estados Unidos criaram os centros de aprendizagem e avaliação para docentes, com o objetivo de oferecer formação ao professor e apoio econômico à escola. Já a Espanha desenvolveu centros de professorado, com o intuito de formar docentes a partir da experiência de outros docentes da própria rede de ensino que haviam sido selecionados por terem desenvolvido projetos considerados inovadores (VAILLANT; MARCELO, 2012). Temos também a experiência de Portugal, que se deu através de uma parceria com as universidades e visava à formação continuada de professores iniciantes, à produção de materiais de apoio e, principalmente, à formação de mentores para acompanhar o trabalho desses professores (REIS; GONÇALVES; MESQUITA, 2012). Todas essas experiências já sofreram avaliações e processos de reconstrução visando a atender às necessidades reais dos professores.

No caso brasileiro, destacam-se as experiências de Sobral/CE e de Campo Grande/MT. Em Sobral, desde 2006, existe uma proposta de formação para os professores iniciantes, com duração de 200 horas, divididas ao longo de três anos. Tem como objetivo propor estudos sobre as questões pedagógicas do cotidiano do professor e ainda ampliar o universo cultural do docente. Já em Campo Grande, o projeto, através de formações coletivas, preocupa-se em apresentar o sistema de ensino, trabalhar as questões pedagógicas do cotidiano e promover o acompanhamento dos docentes, além de utilizar a avaliação dos alunos para validar o trabalho de formação (ANDRÉ, 2012; MIRA; AKSENEN, 2016).

Esses exemplos, encontrados a partir da revisão da literatura, explicitam uma grande diversidade de ações voltadas para a indução profissional docente. Encontram-se relatadas desde algumas estratégias mais contínuas, com duração de longo prazo, até outras mais pontuais, que se limitam ao momento do processo seletivo para o ingresso no magistério; desde ações que trabalham a partir do cotidiano das próprias escolas onde 
esses professores se inserem até outras concebidas como um curso, evidenciando uma lógica mais "escolar".

Em pesquisa desenvolvida por Gatti, Barreto e André (2011), foram encontradas, em três estados brasileiros, ações de indução profissional circunscritas ao processo seletivo para o ingresso no magistério, perspectiva essa na qual se insere a experiência do curso de Formação Básica oferecido pela Escola Paulo Freire.

Apesar de muito recente (criado em 2012), no momento em que realizamos as entrevistas com a gestoras da Escola Paulo Freire (2015), esse curso já estava sofrendo ajustes para melhor se adaptar à rede de ensino e às necessidades dos profissionais iniciantes. Dentre as medidas adotadas estava a diminuição de sua carga horária de 80 para 16 horas.

\begin{abstract}
Ele foi criado dessa forma: é, eu vou ser bem sincera porque a gente também comunga que poderia ter sido diferente, mas foi uma forma que a professora Claudia Costin compreendeu como uma tarefa importante, necessária. Hoje eu faço uma leitura assim: o camarada ainda está como concursando (candidato), ele ainda não é um profissional da educação. Você sabe que isso são 10 dias, 80 horas. Se a pessoa não quiser ser professor? (Gerente B) ${ }^{4}$.
\end{abstract}

Todos $^{5}$ os professores que participaram da nossa pesquisa realizaram o curso em sua primeira versão, com 80 horas de duração, divididas em 10 dias. Segundo pesquisa realizada por Silva (2015), este curso focava algumas temáticas como: orientações curriculares; oficinas temáticas e materiais pedagógicos; mídias e novas tecnologias; e a oficina "Aula nota 10". Os dois primeiros temas visavam a apresentar o contexto da rede de ensino com suas instâncias decisórias, o modelo de organização escolar, a prática de avaliação, os cadernos pedagógicos utilizados pelos professores e ainda visavam a preparar os professores, mesmo que de forma implícita, para a fase seguinte do processo seletivo. Após a conclusão do curso, todos os professores aprovados nessa formação deveriam realizar a prova de aula, de caráter eliminatório.

A temática "mídias e novas tecnologias" pretendia dar autonomia ao docente através do acesso ao site da Secretaria de Educação, que fornece muitos materiais de

4 Para garantir o anonimato, todas as entrevistadas serão designadas por uma letra do alfabeto. As quatro gerentes da Escola Paulo Freire serão designadas pelas letras A, B, C e D. As diretoras de escola pelas letras E, F, G, H e I.

5 Todos os que consideramos, pois temos dois respondentes que fizeram o curso no formato mais recente, de 16 horas, mas que não utilizamos na pesquisa, pois esse número foi visto por nós como insuficiente para a análise.

Educação \& Formação, Fortaleza, v. 4, n. 11, p. 179-196 maio/ago. 2019

DOI: https://doi.org/10.25053/redufor.v4i11.1031

http://seer.uece.br/redufor 
apoio, bem como outras ferramentas pedagógicas que auxiliam o professor na organização de sua prática docente (SILVA, 2015).

A última temática, oficina "Aula nota 10", baseava-se no livro de Doug Lemov Aula nota 10: 49 técnicas para ser um professor campeão de audiência. Sua leitura nos permite destacar, para fins de análise, alguns aspectos que predominam nas técnicas apresentadas: a consideração do professor como centro do processo; a responsabilização do docente pelo sucesso e pelo fracasso escolar; a grande preocupação com 0 desperdício de tempo; a grande preocupação com a organização do espaço para que 0 educador tenha domínio da situação; a exposição em sala de aula apenas dos trabalhos exemplares; e, por fim, a defesa de alguns princípios que deveriam fazer parte da cultura escolar: disciplina, gestão, controle, influência e engajamento.

Ao analisarmos esse material, já nos causou estranhamento o título, visto que põe ênfase na técnica como determinante do sucesso do professor, remetendo a um modelo de educação tecnicista, que vem sendo criticado em nossas instituições de formação de professores desde os anos 1980 e na visão participativa e democrática que temos do processo de ensino-aprendizagem. Na leitura detalhada das técnicas, verificamos que a maioria delas tem ênfase no controle dos estudantes e na disciplina, havendo um silenciar sobre as condições humanas, sociais e políticas nas quais o processo de ensino-

aprendizagem ocorre (CANDAU, 1983). Além disso, o professor torna-se o salvador ou o destruidor de toda a prática de escolarização, desconsiderando-se outros fatores que afetam diretamente a prática docente, a exemplo das condições de trabalho.

Esse modelo de formação segue algumas premissas americanas de interferência externa para melhorar a educação sem a participação da comunidade escolar. Alguns desses programas americanos, como a Escola Charter ${ }^{6}$ e o Teach for America ${ }^{7}$, são fortemente criticados, inclusive muitos especialistas fazem uma releitura dos dados estatísticos que tentam apresentar o sucesso dessas experiências, destacando que elas não atendem à maioria da população (RAVITCH, 2012; ZEICHNER; SAUL; DINIZPEREIRA, 2014).

\footnotetext{
6 Tipo de escola pública independente nos Estados Unidos da América, a qual não é administrada por um distrito escolar.

7 Programas de certificação alternativa para professores que exigem do candidato formação superior (bacharelado), porém sem necessidade de cursos formais de educação.
}

Educação \& Formação, Fortaleza, v. 4, n. 11, p. 179-196 maio/ago. 2019

DOI: https://doi.org/10.25053/redufor.v4i11.1031

http://seer.uece.br/redufor 
Ao entrevistarmos as gestoras da Escola Paulo Freire em 2015, percebemos que, após a realização de algumas edições do curso, esta temática baseada no material "Aula nota 10" já não representava uma carga horária significativa. Segundo estudo realizado por Silva (2015), nas primeiras versões do curso havia uma dedicação de mais de 50\% de sua carga horária às oficinas "Aula nota 10". Entretanto, depois de algumas edições do mesmo, o discurso das gestoras da Escola Paulo Freire apontava para um redimensionamento dessa temática, indicando que ela não deveria mais ser o foco principal da formação, talvez um sinal da constatação do distanciamento dessas técnicas do cotidiano das escolas.

\begin{abstract}
[...] o Nota Dez ele vem ser um aliado, não é uma Bíblia para você seguir, né? É algo que vem para te dar uma possibilidade de repensar o seu fazer: 'Será que eu tenho otimizado melhor o tempo? A minha organização do planejamento?'. Então, eles têm oportunidade de ver, notar ou não, perceber aquilo que realmente tem mais afinidade consigo mesmos, então como essa questão foi lá de 2000, desde 2009, em 2012 foi feita uma organização de formação com alguns profissionais, então são esses profissionais que se formaram, que cresceram, tiveram esse tempo para isso [...]. A gente utiliza esses colegas, chama esses colegas para estarem conosco passando essa proposta, e eles recebem ao final do curso os livros que estão ali na nossa compilação, mas esse não é o carro-chefe do curso. A gente vê isso como mais uma possibilidade. (Gerente B, grifo nosso).
\end{abstract}

Não necessariamente utilizando somente esse fundamento teórico-metodológico. Até porque a gente já deu uma relativizada nisso. Como a gente brinca aqui no Rio de Janeiro, a gente está sempre customizando as questões, porque a rede tem uma indagação muito forte. Aqui tem professores da rede. E você chegar ao professor da rede: 'Faça assim! Faz assado!'. Isso não nos agrada nem é a nossa ideia. A nossa ideia é, para quando o 'cara' não tiver nenhuma ideia, isso aqui não é pernicioso. Você ter um estudo desses, de certa forma, contribui para o professor que não tem ideia de como essas questões se organizam. Agora o compromisso que a gente tem com essa formação é que ele pense sobre isso. (Gerente A).

Corroborando o que está apresentado acima, ao questionarmos as professoras cursistas sobre a oficina "Aula nota 10", detectamos a presença de grupos divergentes quanto à importância dessa temática para a formação; enquanto algumas a consideraram desnecessária, outras viram como uma oportunidade proveitosa. Podemos inferir que uma parte dos professores iniciantes - e ainda inexperientes - apresenta insegurança para ingressar na sala de aula, as quais estão vivendo o "choque do real" (HUBERMAN, 2000), buscando respaldo em algumas técnicas aparentemente "eficazes". Já o outro grupo, talvez 
por apresentar alguma experiência profissional ${ }^{8}$ e conhecer a realidade das escolas, descarta a priori qualquer tipo de "receita" ou técnica preestabelecida.

Ainda pensando nesses dois grupos de professores, um com maior experiência profissional e outro com nenhuma ou inexpressiva experiência, percebemos outro aspecto que pode ser analisado a partir desse prisma. Ao serem indagados sobre a contribuição do curso para a prática pedagógica, $57 \%$ dos respondentes afirmaram que esta contribuiu pouco ou nada e $43 \%$ consideraram que o curso foi relevante para a prática docente. Apesar de haver um maior número de respondentes que consideraram não terem aproveitado os conhecimentos desenvolvidos no curso, também é significativo o número de docentes que afirmaram terem feito uso desses conhecimentos na sua prática docente. Isso nos faz crer, na mesma linha de análise sobre o material "Aula nota 10", que os profissionais ainda inexperientes estão ávidos por novos conhecimentos e dispostos a experimentar o que lhes é sugerido.

Segundo Barth (apud VAILLANT; MARCELO, 2012, p. 124), "[...] os professores principiantes, em seu primeiro ano de exercício, são aprendizes vorazes [...], passados dez anos, talvez acossados e esgotados, fazem-se resistentes à aprendizagem". Esse segundo aspecto citado por Barth talvez justifique a negação da contribuição da formação na prática docente por parte de um número elevado de respondentes, ressaltando que $59 \%$ dos professores participantes têm mais de cinco anos de experiência no magistério, dos quais $61 \%$ têm mais de dez anos de experiência no magistério.

Outro aspecto que nos chamou a atenção foi o desconhecimento que as diretoras por nós entrevistadas possuíam quanto ao curso: apenas uma conhecia bem a proposta dessa formação. Nesse caso, vale salientar que a ciência quanto ao processo não era provinda da relação com os novos professores, mas sim de sua experiência própria, já que havia também participado do processo seletivo para a aquisição de nova matrícula. Todas as outras diretoras conheciam a existência de uma formação básica durante o processo seletivo, estando alheias aos objetivos dessa formação, ao conteúdo trabalhado e ao tempo de duração, além de não reportarem nenhum impacto dessa medida na atuação dos professores iniciantes.

8 Do grupo de professores entrevistado, 59\% possuem mais de cinco anos de experiência no magistério. Então, apesar de ser iniciante nesta matrícula junto à prefeitura do Rio de Janeiro, já possui experiência como docente.

Educação \& Formação, Fortaleza, v. 4, n. 11, p. 179-196 maio/ago. 2019

DOI: https://doi.org/10.25053/redufor.v4i11.1031

http://seer.uece.br/redufor 
Entrevistadora: Você tem alguma informação sobre esse curso? O que elas passaram?

Diretora: Não.

Entrevistadora: Elas nem falam?

Diretora: Não (Diretora F).

Entrevistadora: Mas você acha que é esse curso que eles passaram contribuiu para a prática deles?

Diretora: Acredito que sim. Acredito que contribuiu de alguma maneira para a prática deles, entendeu?

Entrevistadora: Certo. Eles passaram dez dias antes de entrar na sala de aula, antes de... Eles fazem alguma menção de algum material, do que eles aprenderam lá, alguma coisa?

Diretora: Não, para mim não. (Diretora G).

Quando indagados sobre o curso de formação básica como um todo, os professores, em sua maioria, avaliaram-no positivamente, principalmente nos quesitos "organização" (91,6\%) e "formadores" (85,4\%). Essa avaliação talvez se justifique pela proximidade dos formadores com a rede municipal, pois, segundo as gestoras da Escola Paulo Freire, estes são, em muitos casos, professores da própria rede de ensino que já trabalham com a formulação de políticas públicas ou que são indicados pelas CREs, instância que acompanha mais de perto as escolas e conhecedora do trabalho e dos projetos desenvolvidos nelas. Essa proximidade do formador com a realidade da escola faz com que o cursista, mesmo estando fora do espaço da prática docente, comece a conhecer a cultura e o clima escolar presentes na rede municipal de ensino. Segundo Flores e Day (2006 apud REIS; GONÇALVES; MESQUITA, 2012), um dos aspectos cruciais para a construção da identidade docente dos principiantes é a cultura escolar e o acolhimento pelos professores mais experientes. Ao se sentir acolhido pelos mais experientes no espaço profissional que assumirá em breve, o professor desenvolve sua autoconfiança e apresenta maior motivação profissional.

Quanto ao momento de realização do curso, quase $60 \%$ dos respondentes informaram que deveria ser oferecido após o ingresso na rede, quando já estivessem em sala de aula. Consoante Mariconi (2014), a formação do professor iniciante passa por dois momentos, um mais geral, ao conhecer o currículo e questões mais específicas daquele sistema de ensino, e outro que se organiza a partir de um diagnóstico realizado pelo professor para detectar suas necessidades após o início da docência.

De fato, acreditamos que o grupo de docentes compartilhe dessa visão de Mariconi (2014), desejando ter um conhecimento prévio do funcionamento da rede de 
ensino, mas, ao mesmo tempo, sentindo falta de conhecer as necessidades do cotidiano para levá-las ao debate durante o momento de formação. Um dos problemas evidenciados pela pesquisa é que esse curso acontecia antes do término do processo seletivo, logo antes da posse, e muitos cursistas, que já exerciam atividades profissionais, tinham dificuldades para se ausentarem do trabalho por duas semanas, aspecto que pode ser considerado relevante quando ele responde não ser apropriada a realização do curso antes do início da docência. Esse foi o sentimento expressado por uma professora em um dos grupos de discussão:

\begin{abstract}
Entrevistadora: E o curso foi feito antes de você tomar posse? Para todo mundo mesmo?

Professora: Foi antes de tomar posse, para todo mundo, e isso eu achei ruim, porque eu tinha uma boa relação na minha escola, minha diretora me liberou, mas teve gente que trabalhava em escola particular que teve que pedir demissão, porque o diretor não quis liberar. E aí fica complicado para a pessoa pedir demissão, fazer um curso de um concurso que não sabe quando vai ser chamado, se vai ser chamado, né, e fica muito complicado para quem não tem essa flexibilidade. A orientação seria essa, fazer depois da posse, porque aí também reduz a quantidade de pessoas, gasta-se menos dinheiro, porque tem a bolsa, tem o tempo que a gente fica lá, né, paga-se aos palestrantes e aí a sugestão seria muito fazer depois. (Grupo de Discussão 3).
\end{abstract}

Tal percepção deve ter sido expressada também nas avaliações do curso realizadas pela equipe da Escola Paulo Freire e parece ter encontrado eco nas mudanças a nós anunciadas nas entrevistas realizadas.

Mesmo com sua curta historicidade, podemos perceber que há um movimento em torno da instalação de uma política de formação básica e continuada para os professores iniciantes no âmbito da rede municipal do Rio de Janeiro. Esse movimento aponta a necessidade de acolhimento e acompanhamento dos docentes, visando a melhorar as práticas pedagógicas, a criação de um vínculo com a rede de ensino e um processo de construção coletiva de pesquisa na e da prática.

\title{
4 CONSIDERAÇÕES FINAIS
}

A pesquisa teve como principal objetivo analisar as ações propostas pelo sistema municipal de ensino do Rio de Janeiro a partir de 2012, voltadas para a inserção profissional de professores iniciantes.

A análise do percurso de institucionalização da Escola Paulo Freire nos permitiu entender um movimento em torno da instalação de uma política de formação docente 
desenvolvida no âmbito da rede municipal de educação do Rio de Janeiro e a complexa trama que perpassou e perpassa por esse processo. Em seu curto tempo de atividade, essa institucionalização foi marcada pelo cruzamento de projetos e normatizações que evidenciam disputas em torno de concepções de educação, formação e docência, que buscam tomar forma na política docente no contexto carioca.

Em relação às ações voltadas para a inserção profissional e o acompanhamento dos professores, constatamos que o programa implementado com maior visibilidade foi 0 da Formação Básica, compreendido como uma das etapas do processo seletivo para 0 ingresso na rede.

No que se refere à Formação Básica, evidenciamos, de uma maneira geral, uma avaliação positiva desse curso pelos professores que participaram da pesquisa. Contudo, o fato de ser oferecido antes do ingresso na rede foi recorrentemente apontado como um aspecto negativo, gerador de certos obstáculos. Um desses problemas refere- -se à necessidade de o candidato a professor deixar seu emprego para participar do curso em horário integral durante dez dias sem a garantia de aprovação no processo seletivo e de convocação à posse. Outro problema apontado e que também decorre da realização do curso como uma etapa do processo seletivo foi o alto custo para os cofres públicos, nem sempre correspondente ao benefício que o mesmo pode gerar. Lembramos aqui que os candidatos a professores recebem uma bolsa equivalente à metade do salário docente $\mathrm{e}$ que nem todos chegarão a tomar posse do cargo, visto que ainda realizarão uma das etapas do processo seletivo após a conclusão do curso.

Observamos, entretanto, um movimento de reestruturação dessa formação, com redução da carga horária para 16 horas a serem realizadas em apenas dois dias, o que já se efetivou nas últimas edições do curso. Segundo as gestoras da Escola Paulo Freire, a intenção era realizar o restante da formação após o ingresso do professor na rede. Tal movimento estava direcionado a minimizar as dificuldades percebidas por elas ao longo do período em que o curso foi oferecido e que foram apontadas também no decorrer desta pesquisa. Contudo, até o término desta investigação, essa ação de continuidade do curso após o ingresso na rede não havia sido implementada como política de acompanhamento e formação continuada daqueles professores que realizaram essa nova versão da iniciativa. 
A pesquisa revelou que existe um movimento de mudanças em curso, referente principalmente às concepções que orientam as ações promovidas pela Escola Paulo Freire. Os depoimentos, sobretudo das suas gestoras, assinalaram que se buscava, no momento em que o trabalho de campo foi realizado, uma afirmação no sentido de estabelecer um projeto que deslocasse a escola de um lugar meramente subsidiário das ações de formação para uma perspectiva mais ativa de concepção e gestão de processos formativos.

Podemos considerar que há um esforço para a expansão e avanço do projeto em relação ao que foi previsto inicialmente. Esse movimento ocorre em torno de uma afirmação da proposta como uma política propriamente dita. Tal como assinalam Gatti, Barretto e André (2011), o desafio maior é garantir seu assentamento na política docente e educacional em geral, para além de programas e projetos fugazes e abordagens dicotômicas ou binárias.

Nessa perspectiva, uma fragilidade manifesta é o curto espaço de gestão e a personificação desse processo, uma vez que se trata de um projeto intencionalmente de longo prazo, mas que está sob a incumbência de gestoras que trabalham com a periodicidade de um governo, delimitado pelos prazos das eleições municipais. Como dito anteriormente, as gestoras por nós entrevistadas em 2015 exerciam seus cargos havia pouco mais de um $a_{n}{ }^{9}$ e as eleições municipais ocorreram no final de 2016. Atualmente, identificamos que algumas dessas gestoras já não fazem mais parte da equipe da Escola Paulo Freire.

Uma maior participação da sociedade e, principalmente, dos docentes na implementação de políticas públicas voltadas para a docência e legitimação da Escola Paulo Freire poderia romper com a perspectiva segundo a qual a responsabilidade pela implementação de uma política recai quase que exclusivamente nas pessoas que ocupam os cargos gestores e, assim, ampliar a dimensão pública da política docente e educacional.

\section{REFERÊNCIAS}

ANDRÉ, M. E. D. A. Políticas e programas de apoio aos professores iniciantes no Brasil. Cadernos de Pesquisa, São Paulo, v. 42, n. 145, p. 112-129, 2012.

9 A escola foi inaugurada em 2012 e essas gestoras assumiram seus cargos em 2014/2015.

Educação \& Formação, Fortaleza, v. 4, n. 11, p. 179-196 maio/ago. 2019

DOI: https://doi.org/10.25053/redufor.v4i11.1031

http://seer.uece.br/redufor 
CANDAU, V. M. Papel da didática na formação de educadores. In: CANDAU, V. M. (Org.). A didática em questão. 5. ed. Petrópolis: Vozes, 1983. p. 11-57.

CAVACO, M. H. Ser professor em Portugal. Lisboa: Teorema, 1993.

DUBAR, C. A socialização: construção das identidades sociais e profissionais. Lisboa: Porto, 1997.

GATTI, B.; BARRetTO, E. S. S.; ANDRÉ, M. E. D. A. Políticas docentes no Brasil: um estado da arte. Brasília, DF: Unesco, 2011.

HUBERMAN, M. O ciclo de vida profissional dos professores. In: NÓVOA, A. Vida de professores. 2. ed. Lisboa: Porto, 2000. p. 31-61.

LEMOV, D. Aula nota 10: 49 técnicas para ser um professor campeão de audiência. Tradução Leda Beck. São Paulo: Da Boa Prosa: Lemann, 2011.

MARCELO, C. Formação de professores: para uma mudança educativa. Porto: Porto, 1999.

MARCELO, C. O professor iniciante, a prática pedagógica e o sentido da experiência. Formação Docente, Belo Horizonte, v. 2, n. 3, p. 11-49, 2010.

MIRA, M. M.; AKSENEN, E. Z. Processos de inserção à docência nos planos municipais de educação: um estudo exploratório. In: ANPED, Paraná, 2016. Anais... Paraná: UFPR, 2016. p. 1-16.

NÓVOA, A. Desafios do trabalho do professor no mundo contemporâneo. Livreto publicado pelo Sindicato dos Professores de São Paulo, 2007.

RAVITCH, D. Vida e morte do grande sistema escolar americano: como os testes padronizados e o modelo de mercado ameaçam a educação. Tradução Marcelo Duarte. Porto Alegre: Sulina, 2012.

REIS, P.; GONÇALVES, T.; MESQUITA, L. A avaliação do período probatório em Portugal: perspectivas de professores, mentores e gestores. Ensaio: Avaliação e Políticas Públicas em Educação, Rio de Janeiro, v. 20, n. 76, p. 525-546, 2012.

RIO DE JANEIRO. Decreto n. 35.602, de 9 de maio de 2012. Regulamenta o programa anual de bolsas de estudos de mestrado e doutorado. Diário Municipal do Rio de Janeiro, Rio de Janeiro, Poder Executivo, 10 maio 2012.

RIO DE JANEIRO. Escola Paulo Freire [Quem somos]. Rio de Janeiro, [Entre 2012 e 2016]. Disponível em: <http://epf.rioeduca.net/sobrenos.html>. Acesso em: jan. 2016.

RIO EDUCA. Blog A Revolução Acontece. Rio de Janeiro, 2012. Disponível em: <http://www.rioeduca.net/blog.php?tag=sme>. Acesso em: jan. 2016. 
ROLDÃO, M. C.; REIS, P.; COSTA, N. Da incoerência burocrática à eficácia de um dispositivo de supervisão/formação. Estudo do desenvolvimento profissional numa situação de indução. Ensaio: Avaliação e Políticas Públicas em Educação, Rio de Janeiro, v. 20, n. 76, p. $435-458,2012$.

SILVA, C. M. Estratégias de formação para o trabalho docente no município do Rio de Janeiro: o papel da Escola de Formação Professor Paulo Freire. 2015. 68 f. Monografia (Licenciatura em Pedagogia) - Programa de Graduação em Pedagogia, Universidade Federal do Rio de Janeiro, Rio de Janeiro, 2015.

TARDIF, M. Saberes docentes e formação profissional. Petrópolis: Vozes, 2002.

TARDIF, M.; RAYMOND, D. Saberes, tempo e aprendizagem do trabalho no magistério. Educação \& Sociedade: Revista de Ciência da Educação, Campinas, v. 21, n. 73, p. 209$244,2000$.

VAILLANT, D.; MARCELO, C. Ensinando a ensinar: as quatro etapas de uma aprendizagem. Curitiba: UTFPR, 2012.

ZEICHENER, K. M.; SAUL, A.; DINIZ-PEREIRA, J. E. Pesquisar e transformar a prática educativa: mudando as perguntas da formação de professores - uma entrevista com Kenneth M. Zeichner. Revista e-Curriculum, São Paulo, v. 12, n. 3, p. 2211-2224, 2014.

Michele Silva de Avelar (Brasil, Rio de Janeiro, Rio de Janeiro) - Universidade Federal do Rio de Janeiro (UFRJ)

Mestranda em Educação pela UFRJ. Coordenadora pedagógica no Centro de Tecnologia Educacional (CTE) da Universidade do Estado do Rio de Janeiro (UERJ).

Lattes: <http://lattes.cnpq.br/9809127313750814>.

E-mail: <michelesavelar@gmail.com>.

Yrlla Ribeiro de Oliveira Carneiro da Silva (Brasil, Rio de Janeiro, Rio de Janeiro) -
Universidade Federal do Rio de Janeiro (UFRJ)
Pós-Doutora em Educação pela Université Paris Descartes. Integra o Grupo de Estudos e Pesquisas
sobre Profissão e Formação Docente (Geprod). Professora do curso bilíngue de Pedagogia do Instituto
Nacional de Educação de Surdos (Ines).
Lattes: <http://lattes.cnpq.br/9422700857295604>.
E-mail: <heraldo.simoes@uece.br>.

Maria das Graças Chagas de Arruda Nascimento (Brasil, Rio de Janeiro, Rio de Janeiro) Universidade Federal do Rio de Janeiro (UFRJ)

Pós-Doutora em Educação pela Pontifícia Universidade Católica de São Paulo (PUC-SP). Professora associada da Faculdade de Educação da UFRJ.

Lattes: <http://lattes.cnpq.br/0609119454872844>.

E-mail: <luizalfsimoes@gmail.com>.

Recebido em 9 de fevereiro de 2019.

Aceito em 28 de março de 2019.

Educação \& Formação, Fortaleza, v. 4, n. 11, p. 179-196 maio/ago. 2019

DOI: https://doi.org/10.25053/redufor.v4i11.1031

http://seer.uece.br/redufor 